\title{
A Business Model Perspective for ICTs in Public Engagement
}

\section{Paper in press for Government Information Quarterly}

\author{
Panagiotis Panagiotopoulos ${ }^{\text {a, * }}$, Mutaz M. Al-Debei ${ }^{\text {b }}$, \\ Guy Fitzgerald a, Tony Elliman ${ }^{\text {a }}$ \\ ${ }^{a}$ Department of Information Systems and Computing, Brunel University, Uxbridge, Middlesex, \\ West London, UB8 3PH, UK. \\ ${ }^{b}$ Department of Management Information Systems, Faculty of Business, The University of \\ Jordan, Amman 11942, Jordan. \\ * Corresponding author. \\ Email addresses: Panagiotis.Panagiotopoulos@brunel.ac.uk, Mutaz.Al-Debei@ju.edu.jo, \\ Guy.Fitzgerald@brunel.ac.uk, Tony.Elliman@brunel.ac.uk
}

\begin{abstract}
Public institutions, in their efforts to promote meaningful citizen engagement, are increasingly looking at the democratic potential of Information and Communication Technologies (ICTs). Previous studies suggest that such initiatives seem to be impeded by socio-technical integration barriers such as low sustainability, poor citizen acceptance, coordination difficulties, lack of understanding, and failure to assess their impact. Motivated by these shortcomings, the paper develops and applies a business model perspective as an interceding framework for analysis and evaluation. The underlying principle behind this approach is that it is not technology per se
\end{abstract}


which determines success, but rather the way in which the business model of the technological artifact is configured and employed to achieve the strategic goals. The business model perspective is empirically demonstrated with the case of an online petitioning system implemented by a UK local authority. The case illustrates the importance of considering ICTs in public engagement from a holistic view to make them more manageable and assessable.

\section{KEYWORDS}

EGovernment Business Models, Citizen Engagement, Digital Governance, eParticipation, ePetitions, Case Study, Value Networks.

\section{Introduction}

Public institutions have increasingly been considering the use of Information and Communication Technologies (ICTs) to foster citizen engagement. In this endeavor, a plethora of available tools have been applied in a wide range of public governance activities (e.g. Chee, 2008). These initiatives have been driven by the belief that ICTs' potential to enhance democratic processes has yet to be realized (Chadwick \& May, 2003). There is debate about how this can be achieved (e.g. Dutton \& Eynon, 2009; Jaeger, 2005). Within this debate, the concept of technology mediated citizen participation or eParticipation is a new research area within the eGovernment agenda (e.g. Saebo, Rose, \& Flak, 2008).

In addition to participation in policy making, citizen engagement is recognized as an objective covering a broader range of activities such as collaborative service design (e.g. Chan \& Pan, 2008). Public organizations use online means to interact with citizens and provide them with added value elements in different ways from traditional service delivery to political participation 
(Janssen, Kuk, \& Wagenaar, 2008). ICTs for public involvement are not simply a set of new services but an emerging agenda of public administration processes that seek to foster transparency, openness, and legitimacy (e.g. Bingham, Nabatchi, \& O'Leary, 2005).

Although there are some successful cases demonstrating positive results, public participation initiatives are often impeded by barriers such as low adoption, poor sustainability, coordination difficulties, and a lack of assessment of their impact (Macintosh, Coleman, \& Schneeberger, 2009; Saebo et al., 2008). Projects pursuing citizen engagement are as complex to implement as any other eGovernment services (Rose \& Grant, 2010) and have additional difficulties, including targeting stakeholders and integration within the policy making lifecycle (e.g. Andersen, Henriksen, Secher, \& Medaglia, 2007; Macintosh, 2004). There is also the challenge of how to foster engagement through institutional mechanisms (Lowndes, Pratchett, \& Stoker, 2006). According to Carman (2010), for such mechanisms to be meaningful, significant attention needs to be devoted to public perceptions of procedural fairness. Therefore, organizing and cultivating online engagement entails a wide range of critical socio-technical decisions apart from choices over particular tools.

Previous studies have discussed issues of technology customization within different aspects of eGovernment (e.g. Fedorowicz, Gelinas, Gogan, \& Williams, 2009; Meijer \& Thaens, 2010). Further research has built upon the institutionalization and enactment view of technology seeking to explain how technological artifacts are shaped by policies and organizational practices (Cordella \& Iannacci, 2010; Kim, Kim, \& Lee, 2009) ${ }^{1}$. Nevertheless, little previous research has linked citizen engagement strategy to ICT design and operation (Irani, Elliman, \& Jackson,

\footnotetext{
${ }^{1}$ Fountain's (2001) technology enactment framework has particularly generated debates on the topic; see for example Norris (2003).
} 
2007). Furthermore, the open agendas of online engagement (Saebo et al., 2008) complement the broader call by Yildiz (2007) for new eGovernment theoretical approaches to enhance our understanding of policies and actors within complex public sector environments.

Indeed, the rapid pragmatic evolution of online interactions fails to make clear or coherent their underlying logic. Importantly, this chaotic appearance has sometimes resulted in them being ignored in public sector organizations. This paper explores the business model (BM) concept, with its power to link theory and practice, as an approach to create opportunities and foster sustainability in public sector technological initiatives. The underlying principle behind the BM concept is that it is not technology per se which can determine success, but rather the way in which the BM of technological artifact is configured so that strategic objectives can be achieved and aligned with practice. The BM concept represents a holistic view useful for connecting internal structure and functions with the external environment and associated interactions. It has been described as an "abstract representation" (Al-Debei \& Avison, 2010), a "logical story" (Magretta, 2002), or a "blueprint" (Chesbrough \& Rosenbloom, 2002).

For this study, we draw from the unified framework of the BM concept developed by Al-Debei and Avison (2010). We explore its main components within the public sector and particularly examine how BM thinking can enhance the use of ICTs in public engagement. On this basis, a context-specific BM framework is developed which is then empirically applied using the case of an online petitioning system developed by a UK local authority. The practical implications suggest that policy makers can benefit from BMs in order to plan and evaluate manageable institutional mechanisms that will improve the impact of digital governance initiatives.

The rest of this paper is structured as follows. First, Section 2 introduces the business model perspective with respect to eGovernment research and reviews its four dimensions. Section 3 
states the research approach adopted for the case study in Section 4, along with the analysis using the business model as a theoretical lens. Section 5 presents reflections and implications of this study, and Section 6 summarizes and develops issues for future research.

\section{The Business Model Perspective}

The Business Model (BM) concept can be defined as: "an abstract representation of an organization, be it conceptual, textual, and/or graphical, of all core interrelated architectural, co-operational, and financial arrangements designed and developed by an organization presently and in the future, as well all core products and/or services the organization offers, or will offer, based on these arrangements that are needed to achieve its strategic goals and objectives" (Al-Debei, El-Haddadeh, \& Avison, 2008, p.8).

The $\mathrm{BM}$ is important as an effective way of formulating and representing the organization logic behind a particular business or initiative (Shafer, Smith, \& Linder, 2005) whether the organization is for-profit or non-profit (Al-Debei et al., 2008). The BM, if visible and explicit, can be useful in defining and understanding which processes and information systems are appropriate for implementation so as to support strategic choices. However, although the BM is recognized as important in the digital age, designing and applying BMs requires expertise and knowledge of the multiple domains that the model touches upon.

BM thinking has been employed in many different fields, for example, eBusiness (Timmers, 1998), mobile technology (Bouwman, De Vos, \& Haaker, 2008) and eGovernment (Janssen et al., 2008). The latter is discussed in detail in the following section. 


\section{$2.1 \quad$ Business Models for public sector organizations}

The usefulness of the BM concept in eGovernment research has been recognized in a number of studies by Janssen et al. (2008) and Janssen and Kuk (2007, 2008). Although the term BM is traditionally associated with the business world, using it in the public sector context does not imply broader ideas of transferring business-like practices (see Chadwick \& May, 2003; Cordella \& Iannacci, 2010).

In the public sector, there is no competition to serve the citizens or the requirement to generate profits. However, the need to improve public services and foster new ideas and collaborations is particularly relevant. As in the business world, public sector BMs involve the definition of product and service offerings, internal functions and external collaborations. Public sector BMs attempt to describe the ways of delivering online added value to citizens in various areas from service delivery to political participation.

Janssen et al. (2008) develop a taxonomy for analyzing eGovernment BMs and demonstrate its application in a survey of websites in the Netherlands. They conclude that the concept can be valuable in the public sector for describing service provisions and identifying elements for future improvements. However, understanding the BM constituents when planning for, managing, and evaluating digital governance initiatives is still largely unexplored. Janssen et al. (2008) especially recommend conducting in-depth case studies to: (1) capture different underlying BMs, (2) better understand the elements that make up a BM and (3) link the contribution of those elements to the success or failure of public sector digital activities.

Public sector BMs are of particular interest currently because of the changing way that governments are interacting with their citizens. Technological advancements, such as social media tools, have important implications on public strategies for civic engagement (Meijer \& 
Thaens, 2010). Furthermore, it is recommended that citizens are encouraged to undertake public policy initiatives in a bottom-up manner (Dutton \& Eynon, 2009). The next section introduces the BM approach adopted in this study.

\subsection{An integrative framework of the Business Model concept}

The ontological structure of the BM concept signifies a major part of the BM unified framework developed by Al-Debei and Avison (2010). This structure defines four main dimensions encapsulating sixteen components along with their associations that are considered important for analyzing and designing digital BMs. The framework was developed using a content analysis method and deductive reasoning over a range of previous studies.

In this section, the four dimensions are described and then discussed in the context of digital governance. This discussion synthesises the BM framework for public engagement which is summarized in Figure 1.

\subsubsection{Offering citizen engagement effects: the value proposition}

The value proposition is a description of the services an organization offers (or will offer), the elements that intend to add value to the offering, and the nature of the target segment (individuals and organizations) along with their needs. Defining new services is important in terms of name, type, functions, and technical/non-technical requirements. This would help BM designers better understand services and their requirements, thus communicating and delivering them to target segments. The value elements to be conveyed to the target segment also need to be identified and evaluated. 


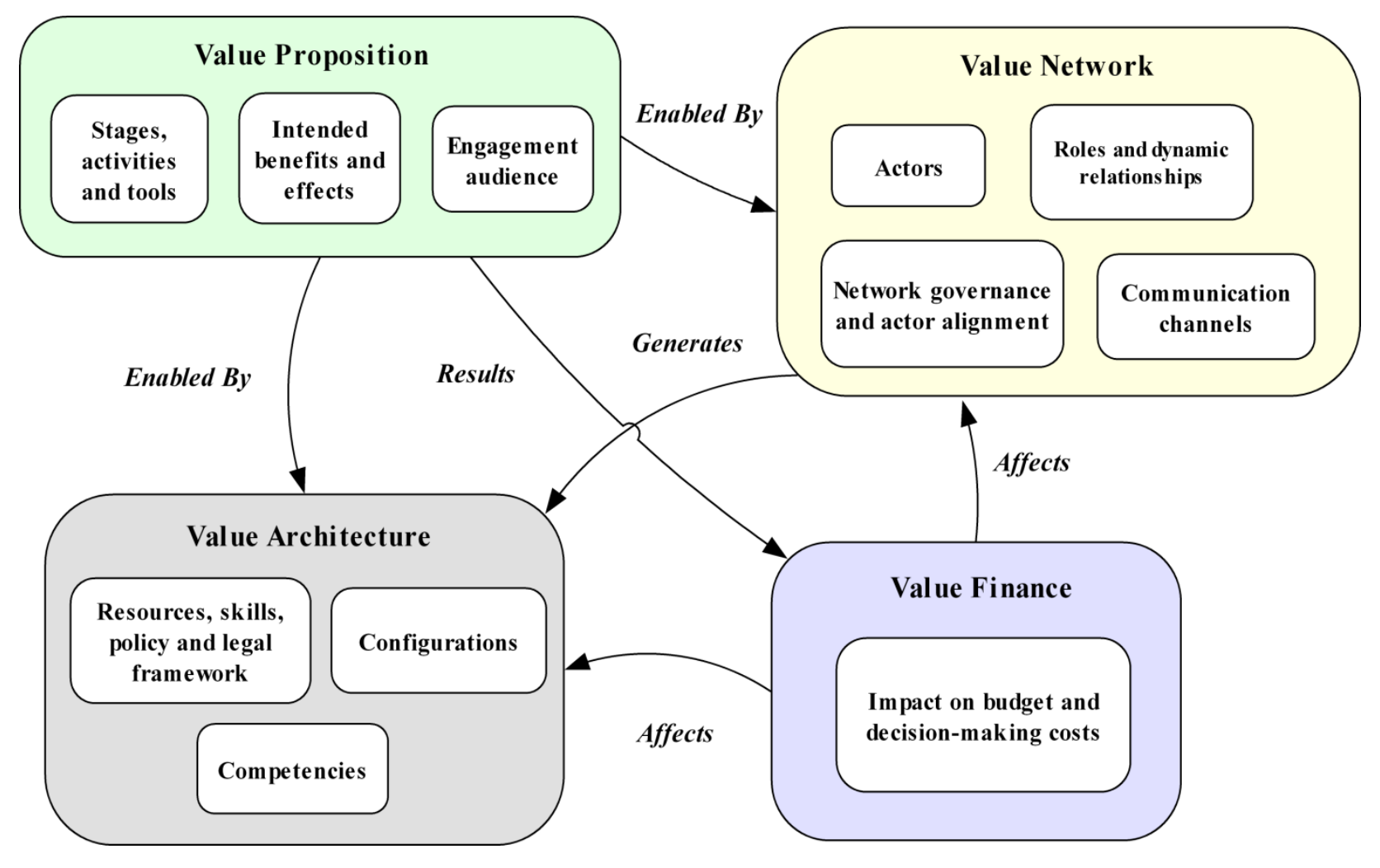

Figure 1 - Business model framework for public engagement.

In digital governance initiatives, the main decisions require choices over stages of the policymaking lifecycle and tools to be explored over a wide available range ${ }^{2}$. Decisions over promoting engagement with particular citizens or citizen groups are strategically and operationally important. For example, in the cases reported by the UK Digital Dialogues evaluation exercise, targeted groups include children, older people, journalists, academics, or other key thematic experts (Miller \& Williamson, 2008). Young citizens form a frequently targeted group (e.g. Macintosh, Robson, Smith, \& Whyte, 2003).

2 Typical focus areas include: petitions (Miller, 2009), consultations (Tomkova, 2009), and deliberations (Rose \& Saebo, 2010). 
The value elements or benefits proposed by participation initiatives are wide-ranging. They evolve around the concept of "civic engagement" which empowers citizen groups to connect with authorities, participate in decision making, and form new groups around common interests (Saebo et al., 2008). Citizens usually have a chance to acquire useful information and specialized resources over issues of public concern and, therefore, they can comprehend and monitor public processes. Such an example is the TheyWorkForYou.com website where the activities and expenses of UK Parliament members are being recorded and compared.

\subsubsection{Involving and aligning actors: building the value network}

The value network is a description of collaborations an organization conducts and maintains, including a description of actors and their communication flows. Value networks are important since designing powerful propositions often calls for combinatory expertise rarely available within a single organization. The concepts identified in this dimension are network-mode, actor, role, relationship, flow-communication, channel, and governance. Network mode defines whether the organization is open or closed in relation to potential collaborations. Organizations also need to identify actors' functional and strategic roles and based on that determine their contribution and eligibility to participate. Appropriate relationships need to be established with selected actors along with suitable channels for material flows. Network governance reveals important information related to power and control aspects.

In digital governance research, the roles of different stakeholders and consistency amongst their (even conflicting) interests and motivations are significant for public sector collaborations (e.g. Fedorowicz et al., 2009; Flak \& Rose, 2005). Previous studies suggest a number of actors participating in value networks led by governmental agencies (e.g. Callanan, 2005). Those for 
example include other governmental agencies at different hierarchies, technological providers, consultancy agencies, citizens and citizen groups such as political parties, community and ad-hoc groups.

Many actors from each category can be involved to form the value network of a public governance initiative and influence its development. The value network can evolve dynamically: the number of actors and the way they are configured may change over time, stimulated by changes in technology, regulatory arrangements, market demands, and so on.

\subsubsection{Configuring resources and creating competences: the value architecture}

The value architecture is a broad plan that specifies all necessary core technological and organizational arrangements in terms of resources and their configurations, as well as competencies that an organization is equipped with. In this dimension, the relevant concepts are resources, configurations, and competencies; all three include both technological and organizational aspects. Resources can already be available within the organization or acquired through value network actors. They might also cover regulative, financial, skills, and other types whether they are tangible or intangible.

The value architecture addresses some of the most persisting challenges for achieving meaningful engagement such as coherence among the different stages of the policy-making life cycle, handling the problem of massive scale and adapting governance structures (Macintosh, 2004). In particular, devoting, assembling, and configuring resources have been recognized as essential in sustaining engagement initiatives beyond pilot implementation stages (e.g. Local E-

Democracy National Project, 2005). The value of resources is significantly leveraged when they are appropriately integrated, particularly when it comes to large-scale activities. For example, 
Peixoto (2009) reports a local authority participatory budgeting exercise where appropriate civil service reorganization proved to be critical for the initiative's success.

\subsubsection{Determining the costs: the value finance}

Finally, the value finance is a description of the arrangements related to economic viability. Total cost of ownership, pricing methods, and revenue structure are the main three concepts from this perspective. In the case of for-profit organizations, this describes the way in which an organization aims to generate revenue and how this revenue is broken down across different stakeholders. For public sector organizations, only the total cost of ownership seems relevant and represents the cost of designing and developing systems plus the cost of operation and maintenance.

The cost of engagement initiatives is becoming increasingly important as the concept is maturing towards the implementation stage. Apart from ownership costs, online engagement may have an impact on decision making costs which are arguably lowered (Kumar \& Vragov, 2009). This, for example, applies when digitizing bureaucratic processes related to citizen engagement (e.g. urban planning activities). In many cases, significant human and administrative redesign costs can be involved when preparing information for consultations or manipulating public input (e.g. setting up forums, maintaining blogs, or creating newsletters and mailing lists) (Andersen et al., 2007).

Having examined the BM dimensions and their relevance to the study context, it is possible to elicit the BM framework as shown in Figure 1. This framework maintains the main concepts from the generic one developed by Al-Debei and Avison (2010) and further specifies each 
dimension within the context of online engagement. The framework's empirical application through the case study is explained in the next section.

\section{Research approach}

This study aims to examine how the business model perspective (Figure 1) can enhance the analysis and evaluation of ICTs in public engagement. To demonstrate the framework's application and examine emerging issues and potential benefits, an empirical in-depth case study was conducted.

\subsection{Research settings}

When examining the design and impact of ICTs, a case study methodology is particularly relevant to illustrate the organizational context in which technologies are embedded and their interactions with associated social processes (Dubé \& Paré, 2003; Yin, 2009). The political and socio-organizational complexity of public sector organizations has established the case study methodology as the leading paradigm in digital government research (e.g. Heeks \& Bailur, 2007).

The study was conducted with a London local authority or London Borough, the Royal Borough of Kingston-upon-Thames, and focused on the authority's ePetitioning initiative (the unit of analysis). Kingston is a small local authority in the south-west part of Greater London with a population of about 167,000. It consists of 16 neighborhoods (wards) each electing three councilors. Following the May 2010 elections, the council administration is divided between the 
leading Liberal Democrat party (27 councilors) and the Conservative party (21 councilors) ${ }^{3}$. Kingston is a perceived prosperous area and benefits from the highest employment rate in London.

The authority's principal motivation to consider online engagement sourced from certain social characteristics: high Internet usage (around 90\%) and youth presence within the borough. Since 2004, Kingston was the first local authority to experiment with online petitioning through its involvement with the Local E-Democracy National Project (2005) (along with Bristol City Council). The aim of this activity was to complement traditional petitioning channels to the council (paper-based petitions) and explore public reception ${ }^{4}$.

This single case was chosen as unique and revelatory (Yin 2009). It is unique from an innovative perspective since Kingston was the first local authority to consider ePetitions. The system's operation for more than six years provides a developed case in comparison with the usually more limited experiences. Kingston's ePetitions are a notable example of using ICTs for engagement, which can inform authorities considering such activities. Hence, the case can reveal insights related to the integration of such initiatives; such an aspect is particularly useful for most English local authorities who, according to 2009 national legislation, have been expected to provide an ePetitioning facility ${ }^{5}$.

${ }^{3}$ Only two out of 33 London Boroughs are led by the Liberal Democrat party as of 2010. Liberal Democrats take a centre to centre-left political position while Conservatives represent the centreright.

${ }^{4}$ Kingston's ePetitions are available at http://epetition.kingston.public-i.tv/ (last accessed 03/2011).

${ }^{5}$ See the Local Democracy, Economic Development and Construction Act (2009). 
This research is exploratory since it aims to empirically validate the BM perspective in terms of demonstrating how its application can provide a holistic understanding of online engagement exercises and enhance their analysis and evaluation (Dubé \& Paré, 2003). The study was informed from the beginning with the BM framework which, although used here as an analytical perspective, it can also be exploited for design purposes depending on the application context (see section 5.2). Therefore, the use of the BM framework here as a theoretical perspective, apart from building explanations, also aims to develop prescriptive elements (Gregor, 2006).

\subsection{Data collection and analysis}

The qualitative data used for the study were collected between January and July 2010. Interviews and documentary analysis were the two equally important sources. To understand the project's context and rationale, the first step was to examine the pilot evaluation by Whyte, Renton, and Macintosh (2005) which included data from interviews, statistics, and a questionnaire. Next, a wide range of available documentation was collected and analyzed: for example, statistics about the system's use, the topics, duration, and signature volume of petitions, as well as the processes for managing the system and handling petitions; the council's structure, meeting minutes, and policies were also available. Furthermore, regulatory and consultation documents from the UK Department of Communities and Local Government were examined.

The semi-structured interviews were conducted with key informants seeking to capture the role of the different internal and external stakeholders influencing the system's use. In particular, the approach to selecting participants was based on examining the multiple perspectives of the various actors involved in the initiative's value network (elaborated on in section 4.2.2). 


\begin{tabular}{|c|c|}
\hline Interviews & Participant role and interview focus \\
\hline \multirow{3}{*}{ Civil Service (5) } & $\begin{array}{l}\text { Democratic Services (3) } \\
\text { Online system and petitioning process management. }\end{array}$ \\
\hline & $\begin{array}{l}\text { IT Department (1) } \\
\text { System integration, technical management and collaboration with the } \\
\text { service provider. }\end{array}$ \\
\hline & $\begin{array}{l}\text { Housing and Planning Applications Department (1) } \\
\text { Many petitions received about planning application topics. }\end{array}$ \\
\hline \multirow{2}{*}{ Councilors (4) } & $\begin{array}{l}\text { Liberal Democrats (3) } \\
\text { Leading the council and responsible for local decision making. }\end{array}$ \\
\hline & $\begin{array}{c}\text { Conservatives (1) } \\
\text { Council opposition. }\end{array}$ \\
\hline $\begin{array}{l}\text { Chair of a local } \\
\text { residents } \\
\text { organization (1) }\end{array}$ & Organized a very popular ePetition at the time of the study. \\
\hline $\begin{array}{l}\text { Non-elected } \\
\text { politicians (2) }\end{array}$ & Organized ePetitions at the time of the study. \\
\hline $\begin{array}{l}\text { Service provider } \\
\text { (1) }\end{array}$ & Outsourcing the system to the council and consulting. \\
\hline
\end{tabular}

Table 1 - Interview participants

Table 1 outlines the participants and their roles. Snowball sampling proved useful (Myers \& Newman, 2007), especially with elected representatives who are generally difficult to engage in research processes (also given that our study included the May 2010 UK general elections). Most 
interviews were taped and transcribed; otherwise, extensive notes were taken. Interviews with public officers lasted around 45-60 minutes on average and interviews with politicians and community leaders around 30 minutes.

The core of the interview agenda, as shown in Figure 2, was derived from the main BM concepts. Each interview adjusted its focus according to the interviewee's particular involvement, role, and availability. Interviews with councilors focused on the system's engagement context in terms of intended benefits, resource allocation, and future developments. Interviews with public officers explored issues of administration, collaborations, and the use of resources. Most councilors and all local community leaders and politicians interviewed were recent system users as principal petitioners. The interview with the service provider drew attention on technical characteristics and how collaboration with the authority is established. A follow-up interview with public officers supported by email contacts summarized the study findings. In general, the study was welcomed by most participants who wanted to reflect on their experiences and understand broader issues of online engagement.

The iterative reflection between the background material and the interviews allowed for the desired degree of data triangulation (Yin, 2009). The documentary analysis consolidated our understanding of the council's rationale to engage with citizens and the dilemmas involved with offering initiatives to serve this purpose. Overall, the most important aspect investigated was the connection between the council's intentions to deliver particular benefits and the way collaborations and alignments were established within the council's potentials, experiences, and institutional culture. 


\begin{tabular}{|c|l|}
\hline $\begin{array}{c}\text { Business } \\
\text { Model } \\
\text { Dimensions }\end{array}$ & \multicolumn{1}{c|}{ Main themes explored } \\
\hline & $\begin{array}{l}\text { - What is the motivation for considering online citizen engagement? What } \\
\text { sort of objectives those initiatives should meet? }\end{array}$ \\
\hline & $\begin{array}{l}\text { How has "citizen engagement" been conceptualized in the case of } \\
\text { ePetitions (in terms of benefits)? }\end{array}$ \\
& $\begin{array}{l}\text { - Did ePetitions have an effect on rethinking the equivalent traditional } \\
\text { process in terms of additional functionalities such as discussion forums? }\end{array}$ \\
& $\begin{array}{l}\text { - Where there any particular choices over target populations (e.g. young } \\
\text { citizens, community groups)? }\end{array}$ \\
\hline & $\begin{array}{l}\text { - What is the role of citizens, citizen organizations and political parties in } \\
\text { generating ideas for such projects? }\end{array}$ \\
\hline - What are the other sources of ideas, e.g. consultants, other authorities or \\
governmental agencies, system providers or academic collaborations?
\end{tabular}

Table 2 - Main interview agenda

For the data analysis part, the elements of the BM concept (Figure 1) were thematically used to classify emerging concepts and build analytical explanations. Feedback was provided to the organization during and after the interviews summarizing the main findings and also making suggestions for improvements. Also, for validity reasons, key interview participants were asked 
to review and comment on an earlier version of this paper. The next section introduces the case and presents the findings structured across the four BM dimensions.

\section{The Case of ePetitioning at the London Borough of Kingston}

A petition is a formal request to an authority signed by one or a number of citizens. Most petitions concern issues related to legislation, policy changes, requests for grants, or even personal issues. EPetitioning, as the online transfer of this process, has been considered one of the most successful practices of the eDemocracy idea. Although ePetitions might be criticized as lacking deliberative mechanisms, they provide an attractive, easy, and transparent way for citizens to raise issues that authorities should consider (e.g. Macintosh et al., 2002).

Petitions are historically embedded in the UK political culture and the Oxford Internet Survey has demonstrated that signing a petition is the most frequent form of online political participation (Dutton, Helsper, \& Gerber, 2009). The UK Prime Minister's ePetitioning website, since its launch in 2006 by Tony Blair's Labour government, attracted millions of signatures in thousands of different topics. In parallel, it generated extensive debate over its usefulness and impact, even among elected representatives and government members (Miller, 2009).

Critics particularly emphasised that the government did not succeed in generating satisfactory answers to many petitions other than links to work in progress. The most popular petition collected about 1.8 million signatures against government's road pricing plans and gained wide media attention. The website was closed in December 2010 by the newly elected coalition government, prior to plans for its re-launch on the main governmental portal Directgov. In contrast, ePetitioning at the local government level seems to be less controversial. 


\subsection{Case background}

The national eDemocracy project covered a wide range of potential tools (e.g. panels and forums). One of the interview participants was a key actor in launching ePetitions and leading the effort nation-wide. In addition to ePetitions, she recalls the project as one of the most extensive of this kind internationally with around 20 more sub-projects. EPetitions, led by Kingston and also piloted by Bristol, were expected to strengthen local democratic processes and examine the impact on different citizen groups. The initial system was the one used by the Scottish Parliament (Macintosh et al., 2002) before the system's provision was assigned to a company.

Most interviewees explicitly stated that what really matters is "what happens to a petition after being submitted" and not the website itself which maintains quite simple technical and usability characteristics. This argument, aligned with the main BM assumption, was elaborated in many different aspects. From the beginning, emphasis was placed on supporting the existing petitioning practice in terms of providing an additional channel. Kingston residents traditionally had the opportunity to raise issues though petitions, either individually or supported by elected representatives. Engagement numbers were seen as the main benefit since the barriers to engage are lowered compared to traditional petitioning. Civil servants and politicians agreed that ePetitions are viewed as another, yet important, way to connect citizens with formal decision making processes and increase participation.

Since its inception, the ePetitioning website has handled more than 70 petitions in addition to the more than 110 paper petitions received in parallel. Each ePetition received 90 signatures on average and many were directly organized or sponsored by local representatives. During the period 2004-2009, the petitioning volume remained quite stable. There is no minimum number 
of signatures required for a petition to be considered. For reasons of access and quality, paper petitions can run in parallel to ePetitions. To increase the website's visibility and invite residents to consider its use, an advertisement effort was also launched at the beginning.

Varieties in the number of signatures are understandable since petitioning topics concern all the council's functions and responsibilities. They might be more or less localized, e.g. issues might be relevant to a few streets or the whole borough. In general, more localized topics are still addressed through paper petitions and ePetitions tend to concern topics of wider interest. This explains to a large extent why the majority of petitions are still submitted through the traditional route.

Indicative petitioning topics include planning applications, traffic arrangements, energy efficiency, recycling, and bus stops. Although localized petitions are normally signed by about 20-30 citizens, there have been cases of petitions managing to attract hundreds or even thousands of signatures. More petitions are usually received around pre-election periods, although certain restrictions might apply on topics that have to be decided after the elections.

An illustrative example during the time of this study concerns a popular petition by a local residents association seeking to proactively prevent plans for opening a new nightclub in their area. The ePetition received nearly 500 online and around 300 paper signatures. Following the formal hearing in the appropriate neighborhood committee, the planning body was notified to take into account this objection in case an application for a nightclub is submitted.

Another example concerns two opposing petitions running in parallel about a traffic application issue. In response to this sign of controversy, the council decided to collect more data on the issue before reaching a formal decision. In this case, the joint discussion of those two petitions in 
a public hearing prevented tensions between residents and clarified future actions to resolve the issue.

Finally, a remarkable case was a petition organized to prevent a local library closure. The petition was led by an opposition councilor and it managed to prevent the closing of the library. It collected more than 700 online and 1800 paper signatures in about three weeks, surprising the council by the level of response. The councilor emphasized the need to increase ePetitions' visibility and effectiveness as they can become an even more central aspect of local political life.

This suggestion seems relevant since, in the UK, reductions in council budgets have generated local debates on services that might need to be terminated. Naturally, objections raised through petitions are expected to increase along with the conflict that such decisions usually bear. This aspect is further discussed in the case analysis and the study implications in section 5.

\subsection{Case analysis}

This section presents the case findings structured according to the main BM dimensions (figure 1).

\subsubsection{Fostering simplicity and responsiveness: the ePetitioning value proposition}

EPetitioning provides a digital space where users can create petitions, sign petitions created by others, and view the outcome of previous petitions. In this way, petitioners can oppose items in the public agenda or raise issues to be considered. Hence, petitions mainly address the agenda setting stage of the policy-making lifecycle. They can also include elements of policy evaluation and monitoring as petitions might request rethinking or periodically reviewing previous policies. 
In other words, citizens are motivated to submit petitions when they feel something should be stopped, started or improved.

EPetitions are initially drafted and confirmed by petitioners and officers before submitted. While they are open for collecting signatures, the details for their public hearing in a council committee are finalized. Following the hearing, official feedback is published online including an optional response from the leading petitioner. Depending on their stage in this process, ePetitions can have different statuses on the website such as "collecting signatures" or "waiting submission." Support for ePetitions is provided through drafting assistance, mailing services for updates, and links to appropriate background information. During the first months of operation, an online discussion forum was also available; it was suspended since moderation proved to be laborintensive.

The council's intention is to view ePetitions in a broader engagement context where more spontaneous activity by citizens is encouraged. In this sense, the authority is willing to also consider ePetitions from other sources apart from the official website. The underlying concept is that all activities which can help people connect with the council are desirable. To ensure this aspect, paper petitions are also archived online in a separate section and, additionally, when both paper and online campaigns are run, petitioners can update the number of paper signatures online. The petition hearing links the online with the offline process. Importantly, it provides a transparent space where formal decisions can be made at the presence of petitioners.

Campaigning for signatures is the responsibility of the petitioner(s) and success to some degree is affected by the number of signatures obtained. However, petitions are treated equally by the authority regardless of their popularity. When petitioners' requests seem straightforward and 
easily applicable or when signatures are very limited, a more informal response might be generated by an appropriate officer.

Considering its main value proposition, ePetitioning is a typical activity where the formation of ad-hoc movements around single issue interests can be significantly facilitated and accelerated (e.g. Anduiza, Cantijoch, \& Gallego, 2009). In this particular implementation context, the added values offered encompass multiple elements:

- Responsiveness, transparency, visibility, and openness. Citizens can easily view petitions online and the signatures collected, including feedback on their outcome. Petitioning processes become more explicit for the public and are accelerated compared to traditional petitions.

- Simplicity, convenience, and geographical reach. The website is more accessible than paper petitions and can enable less localized issues to be addressed by all citizens. In fact, certain users clarified that it would not have been possible to organize the petition otherwise.

- Education and awareness. Citizens can better understand the trade-offs involved in policy-making and realize that such processes might be more complex than initially thought.

As far as the system's target groups are concerned, all borough citizens are eligible to use ePetitions which aim to provide an inclusive channel instead of facilitating targeted involvement. Initially, it was thought that younger citizens would be more receptive and indeed there were some petitions initiated by them, even by school pupils. At later stages, the scope was expanded, although petitions from or about the elderly have not been as frequent as expected. An important 
dimension was high involvement by several councilors who were eager to promote the system and initiate or openly sponsor petitions. Thus, the system provided a means to reinforce their institutional role as coordinators and facilitators of public dialogue.

\subsubsection{The dynamically formed value network}

Figure 2 depicts the initiative's value network. When ePetitions were first considered, the authority took advantage of opportunities for new collaborations. As a result of technology availability and central government funding, the initial collaborations were formed during the system's launch in 2004. Since then, they evolved dynamically mainly due to a change in the provider from an academic partner to a company. The authority was able to benefit from the expertise of academic and technological partners while maintaining control over its processes. This ensured the legitimacy and coordination of newly formed networks while enabling open flow of ideas from users, mainly citizens and politicians. The activity of petitioning itself suits well these aims since it offers the public opportunities to initiate council-led activities.

Councilors from all local parties, especially from the one leading the authority, have so far been quite supportive of the idea by encouraging online petitions and in many cases initiating their own. Hence, they provide political legitimacy. At the beginning, some different views existed about the usefulness of an online system compared to the traditional approach. Those different views didn't lead to actual controversy, only reluctance to recognize the benefits at the short term. In addition, non-elected local politicians grasped the opportunity to communicate their priorities by promoting particular topics during pre-election periods. 


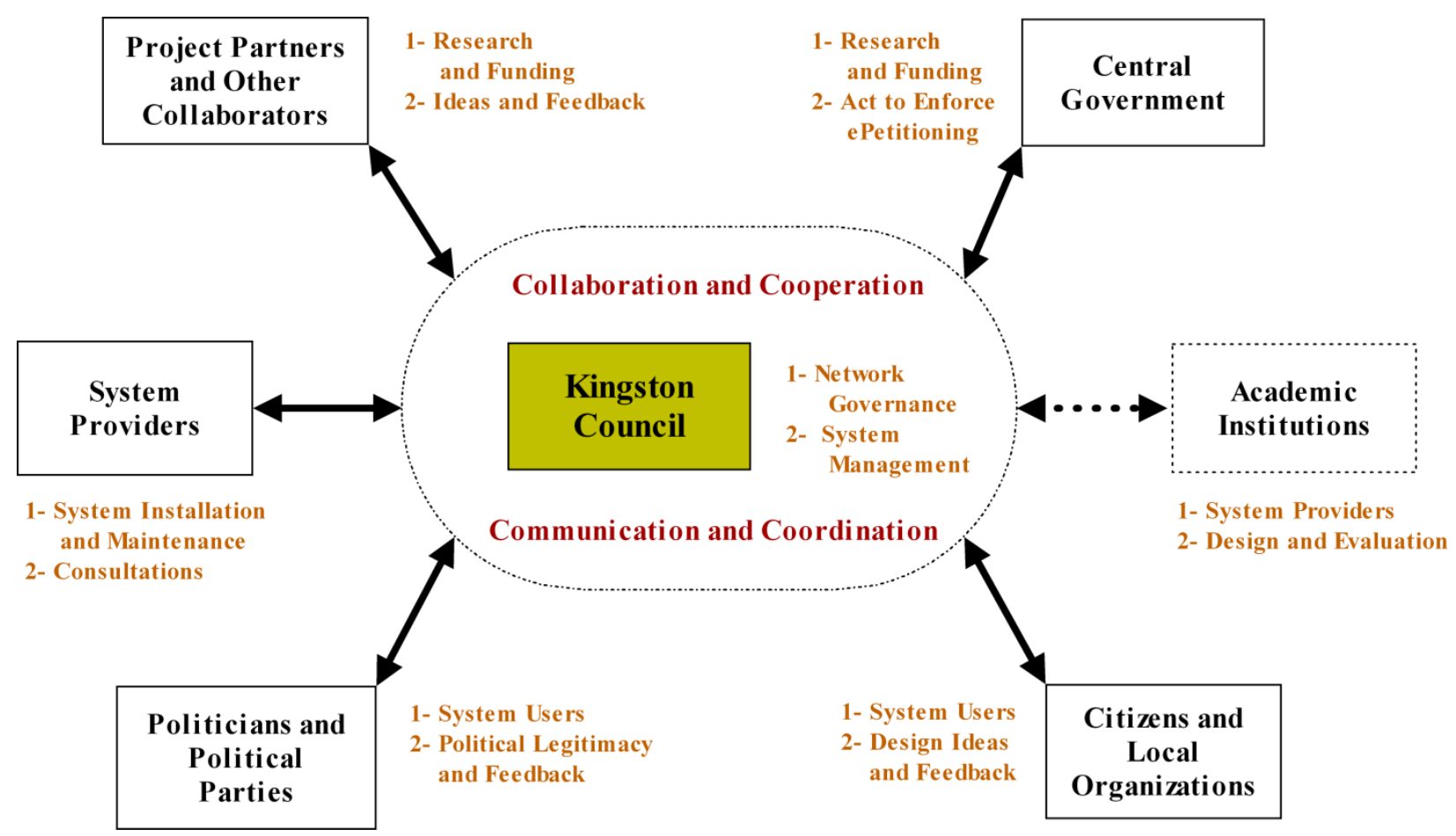

Figure 2 - Kingston's ePetitions value network

Experimentation and open-mindedness proved the best path to achieve citizen uptake and sustain participation. Citizens and local community groups used ePetitions and provided improvement feedback during and beyond the pilot evaluation. Since 2004, most petitions have been initiated by individually motivated citizens who probably do not have access to extensive traditional dissemination mechanisms as local organizations might. As a result, the website enabled them to address their concerns to the local audience. Furthermore, certain successful petitions have been organized by regional or local organizations. Even when such community groups possess limited resources, they are usually able to publicize their campaign in a combination of offline (e.g. leaflets, announcements at events) and online means (e.g. mailing lists, social networks). An integrative campaign can be visible on the web with paper signatures being scanned and published online. 
Finally, the central government, apart from funding, was responsible for the new regulatory framework according to which ePetitioning was made mandatory for English local authorities. Kingston, already complying with the new arrangements, participated in national consultations led by the Department of Communities and Local Government. This is an example of how the actor remained part of the network, but within a different working relationship over time.

The network coordination required local partnerships and public dialogue organized by the council. Petitions are single declarations over a public issue, but in some cases require broader policy examinations and discussions between the different parties involved. Stakeholder interactions within the value network were handled by the Democratic Services, the IT department, and in some cases, by councilors directly.

\subsubsection{Digitizing the petitioning process: the value architecture}

Integration issues were emphasized by the authority which recognized the need to apply a wellestablished process for handling ePetitions. The process required flexibility and minimizing the risk of inconsistency when responding to petitions. Since petitioning was an existing activity, the arrangements for receiving petitions were in place; otherwise new internal processes would have had to be designed.

The minor reorganization elements introduced did not involve major internal competence shifts, in line with prior studies which suggest that such changes tend to be incremental rather than transformational (e.g. West, 2004). Integrating the tailored system within the council's website was one emerging issue handled by the IT department. Another issue was related to the duties of Democratic Services officers who are responsible for the system's administration and handling paper petitions. 
Although after the petition submission the rest of the process remains almost the same, different activities had to be introduced for online petitions to reach that stage. Guidance to the principal petitioner is provided before formally initiating an ePetition. The appropriate departments and officers to handle the petition topic are located and involved politicians are notified. Thus, ePetitions can ensure in advance that they address topics within the council's remit and that arrangements for their discussion are already in place. Before a petition reaches the appropriate committee meeting, it might be channeled to a specialized department (e.g. Legal Services, Housing, or Environmental). Other local organizations, such as the police, might also be consulted or asked to participate in the hearing.

Despite initial concerns over officers' workload, this did not prove to be a significant issue. Officers' continuous involvement and collaboration with providers resulted in an ad hoc optimization of the system's effectiveness and better integration with existing processes. In contrast to some of the cases reported by Gronlund (2003), their increased involvement did not limit support by politicians as officers were responsible for alerting councilors on emerging issues. Knowledge of regulatory arrangements, authorities, and previous policy debates are essential skills for managing petitions, not to mention communication skills with involved stakeholders. Although in our study no such problems were identified, such skills cannot be taken for granted.

Overall, it seems that the authority managed to develop distinct competencies which allowed the intended value elements to be delivered. The process for managing petitions is simple, but bounded and flexible to account for ad hoc communications and coordination between stakeholders (petitioners, politicians, committees, and internal departments). The process was based upon the council's institutional structures, operational framework, and officers' skills. In 
addition, the online system formed a technological competence itself: officers could overview and organize the petitioning process more comprehensively and proactively by monitoring forthcoming petitions and planning in advance. Policy expertise, technology, and institutional authority were the main resources configured to achieve those competencies. Figure 3 summarizes how the petitioning process was digitized.

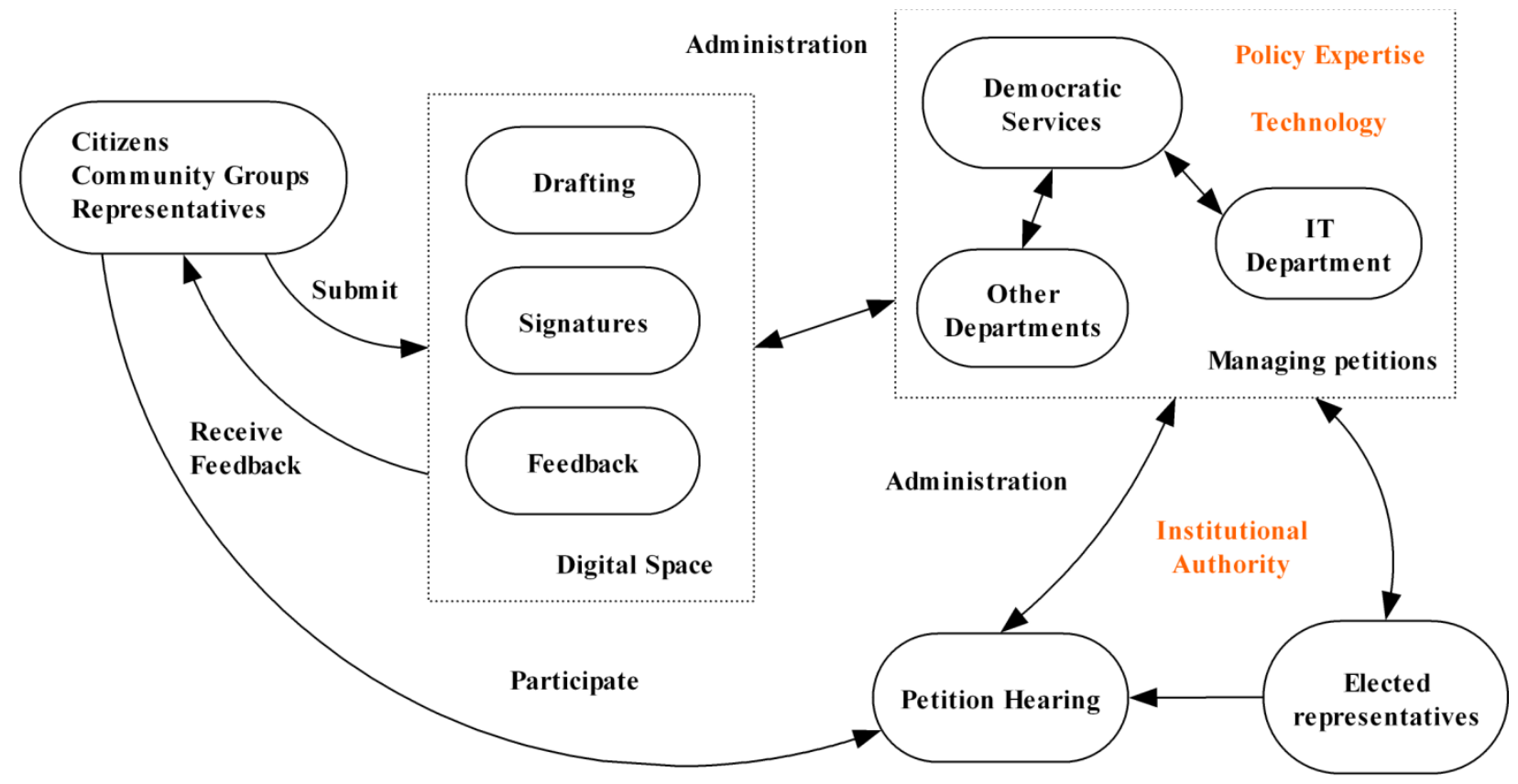

Figure 3 - Digitizing the petitioning process

\subsubsection{Lowering decision-making costs: the value finance}

The project set-up-cost was funded by the national eDemocracy program and ongoing costs were covered by following projects. Although there were concerns over a significant increase in the volume of ePetitions, this was not the case in practice. Managing petitions online is quite cost efficient for the council since the website allows for more petitions to be processed by the same officers. Therefore, although not substantially, it does reduce decision-making costs as observed 
by Kumar and Vragov (2009). No major resource allocation for handling public input was required (Andersen et al., 2007). However, providing support activities such as discussion forums would probably inflict considerable additional costs.

Cost and potential financial gains from eGovernment initiatives was a broader issue within the council. Interviewees agreed that further investments on online engagement require careful considerations. Particularly given the government's intentions to reduce budgets, local authorities need to be able to allocate resources for public participation more strategically. Such decisions cannot neglect the effects on decision-making costs and quality. To this end, beyond initial experimentations over the past years, local authorities are more than ever required to select engagement activities that add real value and also examine their financial impact. This aspect also illustrates the usefulness of BMs for strategic planning purposes. Table 3 summarizes the case analysis which is further discussed in the next section.

\section{Business Model thinking: reflections and implications for policy and}

\section{practice}

The retrospective analysis of Kingston's ePetitions through the BM lens facilitates further observations and reflections. Lessons learnt through the BM perspective highlight elements of successful practices and suggest improvement points. This view contributes to thoroughly identifying, relating, and understanding those elements and points in section 5.1. On this basis, section 5.2 develops implications concerning the usefulness of BMs. 


\begin{tabular}{|c|c|c|}
\hline $\begin{array}{c}\text { Business } \\
\text { Model } \\
\text { Dimension }\end{array}$ & $\begin{array}{l}\text { Relevant } \\
\text { Concepts }\end{array}$ & Kingston's ePetitions \\
\hline 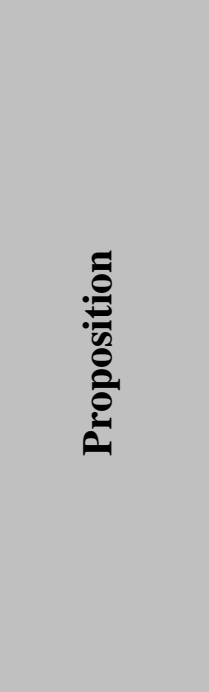 & $\begin{array}{c}\text { Stages, activities } \\
\qquad \begin{array}{c}\text { and tools } \\
\text { Intended } \\
\text { benefits }\end{array}\end{array}$ & $\begin{array}{l}\text { - The initiative maintained clear objectives, but also flexibility } \\
\text { and adaptability in terms of drafting and considering petitions } \\
\text { from different sources. It mainly evolved as an agenda setting } \\
\text { and monitoring exercise. Complementary tools to support the } \\
\text { main activity were under consideration. } \\
\text { - EPetitions offer combined benefits of responsiveness, } \\
\text { geographical reach, simplicity, transparency, political } \\
\text { education and awareness. } \\
\text { - The initiative involved everyone and initially intended more } \\
\text { to young citizens. High local Internet usage provided a strong } \\
\text { motivation. Local organizations and politicians were also } \\
\text { engaged. }\end{array}$ \\
\hline ב̀ & $\begin{array}{c}\text { Network } \\
\text { governance and } \\
\text { actor alignment }\end{array}$ & $\begin{array}{l}\text { - Collaborations were formed dynamically with different actors } \\
\text { providing funding, technical and integration expertise through } \\
\text { evolving relationships. } \\
\text { - Governance was controlled by the authority but maintained } \\
\text { open attitude to new sources of ideas. } \\
\text { - Value network changes were stimulated by technological } \\
\text { advancements and regulatory arrangements. } \\
\text { - Citizens provided feedback on design and implementation } \\
\text { issues. Politicians and political parties were supportive and } \\
\text { provided legitimacy to the initiative. } \\
\text { - Internal and external communications combined online and } \\
\text { offline means. The petition hearing event was the main } \\
\text { communication between citizens and politicians. }\end{array}$ \\
\hline
\end{tabular}




\begin{tabular}{|c|c|c|}
\hline & Resources & Value \\
Configuration & $\begin{array}{c}\text { - EPetitions were based upon the well-established existing } \\
\text { process, but allowed better monitoring by officers. } \\
\text { - Continuous involvement by officers and politicians was } \\
\text { important for better configuring the available technology. } \\
\text { Technological and structural competencies were developed. }\end{array}$ \\
\hline & $\begin{array}{c}\text { Competencies } \\
\text { Impact on } \\
\text { budget and }\end{array}$ & $\begin{array}{c}\text { - Infrastructure funding was provided through different } \\
\text { collaborations, e.g. central government. } \\
\text { - ICT investments were issues of ongoing consideration by the } \\
\text { authority. Yet, the impact on decision-making costs was } \\
\text { difficult to be assessed. }\end{array}$ \\
\hline
\end{tabular}

Table 3 - Case study summary

\subsection{Lessons learnt from the Kingston case}

The BM analysis highlights how it is not the technological artifact on its own, but instead the whole ePetitioning design that allows the citizen engagement effect to be communicated and the council's online interaction objective to be accomplished. At the first level, applying the BM framework allows the identification of elements which contributed to the initiative's local integration and sustainability.

The ePetitioning success and popularity comes from the fact that it is a formal process coordinated by the authority but led by citizens themselves who are empowered to address their concerns and gather around single interest issues in a convenient way. The system itself is not technically sophisticated and, as some interviewees pointed out, of limited value on its own. As illustrated in the value architecture analysis, what really matters is the council's ability to 
integrate this infrastructure and apply a process to handle ePetitions in parallel with paper petitions. Furthermore, the structural simplicity and flexibility of the petitioning process, combined with technological competencies, enabled officers to manage and monitor with ease.

The activity's value proposition was clear as to the added values it intended to deliver, which in turn were enabled through developed competencies. To achieve these competencies, the council reconfigured resources, namely institutional authority, policy expertise, and technology. The value network shows how different stakeholders contributed to the initiative. Collaboration with external actors within and outside the authority provided important benefits such as political legitimacy, funding, and operational feedback. The role of political leadership was also significant: the authority led that particular initiative nationally at the pilot stage.

At the second level, the BM analysis allows for the identification of potential improvement points and elements which require more careful considerations. One such theme here, coming from the value proposition dimension, concerns assistance for campaigning petitions, an issue also mentioned during the system's pilot evaluation. Although disseminating petitions is not the authority's responsibility, the positive impact on local democratic processes could be enhanced if users had additional tools to effectively distribute their concerns and reflect more informed opinions on topics raised. Increasing the visibility of petitions through complementary channels can further ensure that the widest possible spectrum of local actors can be reached and consulted even if not physically able to attend petition hearings. To this direction, possible additional functionalities could include discussion forums, other alert mechanisms (e.g. an ePetitioning bulletin), and assistance to campaign petitions through means such as social networks. The latter seems to be of increasing popularity and can lead to wider support and raising awareness, even beyond official signature numbers (Panagiotopoulos, Sams, Elliman, \& Fitzgerald, 2011). 
In addition, the value finance dimension shows that the system's existence has yet to be established over a long-term financial model which takes into account the impact on decisionmaking costs and quality. Although this has not yet emerged as a real issue, it might affect future decisions on digital initiatives especially due to aforementioned circumstances of public sector budget reductions. Increasing the system's visibility and strengthening even more collaborations with local communities were also identified as potential points of improvement.

In the ePetitioning case there were almost no complaints about how petitions were handled, only some misunderstandings with citizens having the expectation that their petitions would influence formal policy making directly and in a binding way. In line with Carman's (2010) findings, due to the nature of advocacy engagement forms such as petitions, procedural fairness can be the major feature to ensure sustainable participation ${ }^{6}$. This is because, despite citizens contributing with their petitions, final decisions actually remain with the authority. As a result, the engagement value proposition is not merely significant for citizens' expectations, but also interwoven with wider inferences about political institutions themselves.

This key issue from the case analysis highlights how eParticipation can be meaningful and positive for authorities when comprehensive planning and evaluation is involved. In this direction, BMs can contribute towards avoiding unrealistic expectations and preparing more systematically for engagement tools. The next section elaborates on the usefulness of BMs in this particular context.

\footnotetext{
${ }^{6}$ Carman (2010, p. 734) explains that: “Advocacy democracy is marked by citizen participation in the formulation of policies, though citizens are not the final decision makers."
} 


\subsection{The usefulness of Business Models}

As explained in the introduction, some of the major barriers associated with digital governance initiatives are low adoption, poor sustainability, coordination difficulties, and lack of impact assessment. BM thinking can contribute to overcoming those barriers. First of all, BMs traditionally serve as abstract representation of strategies for benchmarking and taxonomical purposes (Janssen et al., 2008; Al-Debei \& Avison, 2010). They provide a holistic view of digital initiatives that takes into consideration relationships amongst different aspects. Hence, they can be used as communication mechanisms which enhance coordination and allow intentions and decisions to be disseminated.

When policy makers apply BM thinking, they can draw attention to the implications of the different BM dimensions. This is an important characteristic that allows them to split the strategy implementation into manageable parts and look at the whole design from a wider perspective also considering trade-offs. For instance, problems of developing competencies or acquiring infrastructure might require involving additional actors in the value network, for example, partnerships with community groups or political organizations.

In particular, the BM approach can substitute ad hoc developments and contribute to the evaluative and normative agenda of eParticipation (Saebo et al., 2008). BMs for public engagement offer the opportunity to group emerging issues, explain why current engagement efforts succeed or fail, and also guide future implementations. In this respect, the benefits of BM thinking can tackle the challenges of sustainability and adoption.

As a framework for analysis, BMs can contribute to the evaluation aspect which is a decisive factor for achieving sustainability (Macintosh et al., 2009; Saebo et al., 2008). Measuring the impact of online engagement has always been problematic and subject to different views, 
especially in terms of linking online and offline activities. BMs can effectively facilitate this connection. For example, in the Kingston case, petitioning was a combination of online and offline channels built upon similar, but explicitly different models.

Therefore, with respect to the evaluation aspect, authorities can rethink existing initiatives or set up in advance realistic objectives for new ones. Using BMs, it is possible to identify potential mismatches from theory to practice at different levels of granularity. Insufficient BM thinking or neglected dimensions can explain some of the current shortcomings. In many cases, clear proposition elements are not formulated. In others, it proves difficult to seek expertise from collaborators or motivate citizens. Maintaining network coordination can also emerge as a challenging task; it can be impeded by barriers such as unclear roles, diverse interests, or marginalizing politicians (Callanan, 2005; Dawes \& Prefontaine, 2003; Nyholm \& Haveri, 2009). The value network dimension of BMs entails identification and description of involved actors, their role, relationship, and communication flows. Hence, it can contribute to recognizing and overcoming such barriers.

As a framework for design, BMs can assist policy makers capture the value and impact of new technological initiatives and prepare public organizations more systematically for them. This is because BM thinking broadens the perspectives for identifying the institutional mechanisms that can cultivate citizen participation in a meaningful way both for citizens and authorities. Such a challenge is imperative for converging spontaneous political activity with formal policy making (e.g. Dutton \& Eynon, 2009; Macintosh et al., 2009). As mentioned, the ePetitioning activity itself is an excellent example of this: the response process is coordinated by the authority, but citizens themselves decide about specific petitioning topics. Further on this, in Kingston, ePetitions were thought of as a potential catalyst to enable broader efforts to connect with 
citizens since they drew attention and focus over diverse topics within local democratic processes. For example, input from petitions is being used for future consultations or planning applications.

Despite its usefulness as a design framework, BM thinking does not aim to transfer popular practices as success stories within and across different initiatives. Providing general prescriptions contradicts previous warnings on acontextual universal ICT strategies which neglect wider implicated forces around technology innovations (e.g. Avgerou, 2001). Particularly when it comes to public organizations, institutional characteristics and socio-political conditions are always embedded in corresponding BMs-related decisions. For example, specific value network relationships might be mandatory (e.g. to collaborate with the central government). Linking wider social, political and economic forces with the way BMs are designed and configured should not be neglected ${ }^{7}$.

\section{Summary and conclusion}

In this paper, the BM perspective was explored as a theoretical lens to understand, analyze, and stimulate ways of thinking on the use of ICTs in public engagement. For this purpose, we drew from the Al-Debei and Avison (2010) integrative framework of the BM concept and developed a context-specific framework. The case of Kingston's ePetitions was presented to illustrate the potential of BMs and BM thinking by providing a notable empirical example of online

${ }^{7}$ Currie (2004, p. 264) specifically notes that BMs can be examined "from a wider societal and inter-organizational context, and not simply at the level of the firm, business unit or decisionmaking practices of individuals." 
engagement tools. The study suggests that BM thinking, as a view on technological initiatives, can be beneficial to organize and evaluate the impact of digital governance activities.

This paper addressed the call to conduct in-depth studies which capture elements that compose BMs (Janssen et al., 2008). The integrative BM framework adopted here provides a good start to unite the analytical dimensions proposed by Janssen \& $\operatorname{Kuk}(2007,2008)$. Additionally, the motivation was to increase consensus over public sector BM elements and make it less independent of taxonomies which might change over time.

The BM principle of technological artifacts being configured to achieve strategic goals complements previous approaches in eGovernment research. Similar to the enactment view of technology, the BM concept emphasizes the ways in which strategies and structures enable technological characteristics to become part of functions and operations (Fountain, 2001; Cordella \& Iannacci, 2010). Complementary, BMs describe and communicate the transition between policies and their operationalization details.

This study has three main limitations. The first comes from the fact that the single case examined is in some of its aspects exceptional and in any case constrained by the UK local government context. The second relates to the BM framework's general applicability. Regardless of the context-specific model developed in Figure 1, whether such a generic framework is optimal for organizations across different hierarchies remains an open one. The third limitation comes from the fact that our study, despite certain positive indications, does not entail systematic evaluation of citizens' views on the ePetitioning initiative. As a result, there is limited knowledge on how the intended BM elements were actually communicated to citizens.

One interesting direction for future research is validating and focusing the BM framework across different technological and socio-political settings. The framework remains generic enough to be 
useful and inclusive of ICT-enabled engagement efforts. Starting from this framework, depending on particular tools and context, more specific models can be built. For example, this can relate to different levels of context (e.g. national) or to historical studies of how BMs evolved dynamically stimulated by changes in technologies or institutional structures.

Another interesting direction might be to exploit BM thinking in assessing citizens' responses and expectations regarding participation. This assessment could more comprehensively link the impact of BM design with citizen acceptance by examining the benefits that citizens perceive, as well as their understanding of engagement processes. Such examinations can be complemented by overview research that uses elements of BM thinking to survey the adoption of particular characteristics behind digital governance initiatives; Janssen et al. (2008) also point to this direction in their more broad survey of eGovernment BMs in the Netherlands.

Finally it should be noted that, although this paper focuses on the citizen participation aspects of eGovernment research, the conclusions could potentially be extendible beyond this domain. Studies of emerging public sector BMs can be undertaken on recent eGovernment initiatives to facilitate the establishment of closer links between theory and practice. Moreover, the BM concept can be relevant for other institutional actors such as political parties, trade unions, or other communities which face similar challenges in their online interactions.

\section{Acknowledgments}

The authors acknowledge interview participants from the London Royal Borough of Kingston and are grateful to Mary Reid and Ann Sweeney for significantly facilitating the research process. The authors are also grateful to Professor Marijn Janssen for his comments on earlier drafts of this paper. An initial version of this research, focusing mainly on the theoretical 
perspective, was presented at the Transforming Government Workshop, March 2010, Brunel

University, London.

\section{REFERENCES}

Al-Debei, M. M., \& Avison, D. (2010). Developing a unified framework of the business model concept. European Journal of Information Systems, 19(3), 359-376.

Al-Debei, M. M., El-Haddadeh, R., \& Avison, D. (2008). Defining the business model in the new world of digital business. $14^{\text {th }}$ Americas Conference on Information Systems, (AMCIS'08), Toronto, Canada.

Andersen, K. V., Henriksen, H. Z., Secher, C., \& Medaglia, R. (2007). Costs of E-Participation: The management challenges. Transforming Government: People, Process and Policy, 1(1), 29-43.

Anduiza, E., Cantijoch, M., \& Gallego, A. (2009). Political participation and the Internet. Information, Communication \& Society, 12(6), 860-878.

Avgerou, C. (2001). The significance of context in information systems and organizational change. Information Systems Journal, 11(1), 43-63.

Bingham, L. B., Nabatchi, T., \& O'Leary, R. (2005). The new governance: Practices and processes for stakeholder and citizen participation in the work of government. Public Administration Review, 65(5), 547-558.

Bouwman, H., De Vos, H., \& Haaker, T. (2008). Mobile service innovation and business models. Heidelberg: Springer-Verlag Berlin.

Callanan, M. (2005). Institutionalizing participation and governance? New participative structures in local government in Ireland. Public Administration, 83(4), 909-929.

Carman, C. (2010). The process is the reality: Perceptions of procedural fairness and participatory democracy. Political Studies, 58(4), 731-751.

Chadwick, A., \& May, C. (2003). Interaction between states and citizens in the age of the Internet: "E-Government" in the United States, Britain, and the European Union. Governance, 16(2), 271-300.

Chan, C. M. L., \& Pan, S. L. (2008). User engagement in E-Government systems implementation: A comparative case study of two Singaporean E-Government initiatives. Journal of Strategic Information Systems, 17(2), 124-139.

Chee, W. P. (2008). A framework of ICT exploitation for E-Participation initiatives. Communications of the ACM, 51(12), 128-132.

Chesbrough, H. W., \& Rosenbloom, R. S. (2002). The role of the business model in capturing value from innovation: Evidence from Xerox Corporation's technology spin-off companies. Industrial and Corporate Change, 11(3), 529-555. 
Cordella, A., \& Iannacci, F. (2010). Information systems in the public sector: The E-Government enactment framework. Journal of Strategic Information Systems, 19(1), 52-66.

Currie, W. L. (2004). The organizing vision of application service provision: A process-oriented analysis. Information and Organization, 14(4), 237-267.

Dawes, S. S., \& Prefontaine, L. (2003). Understanding new models of collaboration for delivering government services. Communications of the ACM, 46(1), 40-42.

Dubé, L., \& Paré, G. (2003). Rigor in information systems positivist case research: Current practices, trends, and recommendations. MIS Quarterly, 27(4), 597-635.

Dutton, W. H., \& Eynon, R. (2009). Networked individuals and institutions: A cross-sector comparative perspective on patterns and strategies in government and research. The Information Society, 25(3), 198-207.

Dutton, W. H., Helsper, E. J., \& Gerber, M. M. (2009). The Internet in Britain: 2009. University of Oxford: Oxford Internet Institute.

Fedorowicz, J., Gelinas, U. J. J., Gogan, J. L., \& Williams, C. B. (2009). Strategic alignment of participant motivations in E-Government collaborations: The Internet payment platform pilot. Government Information Quarterly, 26(1), 51-59.

Flak, L. S., \& Rose, J. (2005). Stakeholder governance: Adapting stakeholder theory to the EGovernment field. Communications of the Association for Information Systems, 16, 642-664.

Fountain, J. (2001). Building the virtual state: Information technology and institutional change. Washington, DC: Brookings Institution Press.

Gregor, S. (2006). The nature of theory in information systems. MIS Quarterly, 30(3), 611-642.

Gronlund, A. (2003). Emerging electronic infrastructures: Exploring democratic components. Social Science Computer Review, 21(1), 55-72.

Heeks, R., \& Bailur, S. (2007). Analyzing E-Government research: Perspectives, philosophies, theories, methods, and practice. Government Information Quarterly, 24(2), 243-265.

Irani, Z., Elliman, T., \& Jackson, P. (2007). Electronic transformation of government in the U.K.: A research agenda. European Journal of Information Systems, 16(4), 327-335.

Jaeger, P. T. (2005). Deliberative democracy and the conceptual foundations of electronic government. Government Information Quarterly, 22(4), 702-719.

Janssen, M., \& Kuk, G. (2007). E-Government business models for public service networks. International Journal of E-Government Research, 3(3), 54-71.

Janssen, M., \& Kuk, G. (2008). E-Government business models: Theory, challenges and research issues. In M. Khosrow-Pour (Ed.), E-Government diffusion, policy, and impact: Advanced issues and practices (pp. 1-12) IGI Global.

Janssen, M., Kuk, G., \& Wagenaar, R. W. (2008). A survey of web-based business models for EGovernment in the Netherlands. Government Information Quarterly, 25(2), 202-220.

Kim, S., Kim, H. J., \& Lee, H. (2009). An institutional analysis of an E-Government system for anti-corruption: The case of OPEN. Government Information Quarterly, 26(1), 42-50. 
Kumar, N., \& Vragov, R. (2009). Active citizen participation using ICT tools. Communications of the ACM, 52(1), 118-121.

Local Democracy, Economic Development and Construction Act. (2009). Retrieved 2010, 15/9, from http://www.opsi.gov.uk/acts/acts2009/ukpga_20090020_en_1

Local E-Democracy National Project. (2005). Barriers to E-Democracy: Local government experiences and responses, Local E-Democracy National Project.

Lowndes, V., Pratchett, L., \& Stoker, J. (2006). Local political participation: The impact of rules-in-use. Public Administration, 84(3), 539-561.

Macintosh, A. (2004). Using information and communication technologies to enhance citizen engagement in the policy process. In J. Caddy, \& C. Vergez (Eds.), Promise and problems of eDemocracy: Challenges of online citizen engagement (pp. 19-142) OECD.

Macintosh, A., Coleman, S., \& Schneeberger, A. (2009). eParticipation: The research gaps. In A. Macintosh \& E. Tambouris (Eds), Proceedings of the 1st International Conference on eParticipation, LNCS 5694 (pp 1-11) Springer-Verlag.

Macintosh, A., Malina, A., \& Farrell, S. (2002). Digital democracy through electronic petitioning. In W. J. McIver, \& A. K. Elmagarmid (Eds.), Advances in digital government (pp. 137-148) Springer US.

Macintosh, A., Robson, E., Smith, E., \& Whyte, A. (2003). Electronic democracy and young people. Social Science Computer Review, 21(1), 43-54.

Magretta, J. (2002). Why business models matter. Harvard Business Review, 80(5), 86-92.

Meijer, A., \& Thaens, M. (2010). Alignment 2.0: Strategic use of new technologies in government. Government Information Quarterly, 27(2), 113-121.

Miller, L. (2009). E-Petitions at Westminster: The way forward for democracy? Parliamentary Affairs, 62(1), 162-178.

Miller, L., \& Williamson, A. (2008). Digital dialogues third phase report: August 2007 - August 2008, Hansard Society.

Myers, M. D., \& Newman, M. (2007). The qualitative interview in IS research: Examining the craft. Information and Organization, 17(1), 2-26.

Norris, D. F. (2003). Building the virtual state... or not?: A critical appraisal. Social Science Computer Review, 21(4), 417-424.

Nyholm, I., \& Haveri, A. (2009). Between government and governance - local solutions for reconciling representative government and network governance. Local Government Studies, 35(1), 109-124.

Panagiotopoulos, P., Sams, S., Elliman, T., \& Fitzgerald, G. (2011). Do social networking groups support online petitions? Transforming Government: People, Process and Policy, 5(1), 20-31.

Peixoto, T. (2009). Beyond theory: E-Participatory budgeting and its promises for EParticipation. European Journal of ePractice, 7, 55-63. 
Rose, J., \& Saebo, O. (2010). Designing deliberation systems. The Information Society, 26(3), 228-240.

Rose, W. R., \& Grant, G. G. (2010). Critical issues pertaining to the planning and implementation of E-Government initiatives. Government Information Quarterly, 27(1), 26-33.

Saebo, O., Rose, J., \& Flak, L. S. (2008). The shape of eParticipation: Characterizing an emerging research area. Government Information Quarterly, 25(3), 400-428.

Shafer, S. M., Smith, H. J., \& Linder, J. (2005). The power of business models. Business Horizons, 48(3), 199-207.

Timmers, P. (1998). Business models for electronic markets. Electronic Markets, 8(2), 3-8.

Tomkova, J. (2009). E-Consultations: New tools for civic engagement or facades for political correctness? European Journal of ePractice, 7, 45-55.

West, D. M. (2004). E-Government and the transformation of service delivery and citizen attitudes. Public Administration Review, 64(1), 15-27.

Whyte, A., Renton, A., \& Macintosh, A. (2005). E-Petitioning in Kingston and Bristol: Evaluation of E-Petitioning in the local E-Democracy national project, Napier University.

Yildiz, M. (2007). E-Government research: Reviewing the literature, limitations, and ways forward. Government Information Quarterly, 24(3), 646-665.

Yin, R. (2009). Case study research: Design and methods (4th ed.). California: SAGE. 